\title{
2007-2008 Küresel Finansal Krizin Öngörülebilirliği Üzerine Tartışmalar
}

\section{7-2008 Discussions on Predictability of The Global Financial Crisis}

\section{Gülden POYRAZ ${ }^{1}$ (}

\section{öz}

Son finansal kriz ekonomik teori ve politikayla ilgili önemli tartışmalara yol açmıştır. En önemli tartışmalar 'kriz neden öngörülemedi?' sorusu üzerine yoğunlaşmıştır. Bu çerçevede çalışmada 2007-2008 küresel finans krizinin neden öngörülemediği sorusu 3 farklı görüşle ele alınmaktadır. Bu görüşlerden ilki, krizin genel olarak iktisatçılar tarafından öngörülemediği ve son finansal krizin akademisyenler ve politika yapıcıların çoğu için sürpriz olarak ortaya çıktığını ifade etmektedir. Diğer bir görüş, krizin bazı iktisatçılar tarafından öngörüldüğü, fakat bu öngörülerin dikkate alınmadığı şeklindedir. Son olarak ve tümüyle farkıı bir görüş ise iktisadın/iktisatçıların kriz öngörüsünde bulunmasının gerek olmadığını ifade eden yaklaşımdır. Çalışma ayrıca, iktisatçıların ekonomiyi analiz etme ve analizlerini formüle etmede kullandıkları yöntemlerin de bir tartışmasını sunmaktadır.

Anahtar kelimeler: Küresel finansal kriz, Ana-akım İktisat, Makroekonomik modeller, İktisadın krizi, Stratejik görmezden gelme, Dinamik Stokastik Genel Denge (DSGE) modelleri

Jel Code: F3, F31, G01

\section{ABSTRACT}

The recent financial crisis has triggered significant debates concerning economic theory and policy. The most important discussions focused on the question: 'why was the crisis not foreseen?'. In this context, the question of why the 2007-2008 global financial crisis was not foreseen is addressed from three different perspectives. The first view is that the crisis could not be predicted by economists in general and that the recent financial crisis emerged as a surprise for most of the academicians and policy makers. Another view is that the crisis was foreseen by some economists, but these predictions were not taken into account. Finally, an entirely different view is the approach that states that economics / economists do not have to predict the crisis. The study also provides a discussion of the methods used by economists in analysing the economy and formulating their proposals.

Keywords: Global financial crisis, Mainstream economics, Macroeconomic models, Crisis of economics, Strategic ignorance, Dynamic Stochastic General Equilibrium models

Jel Code: F3, F31, G01
Bu çalışma, İstanbul Üniversitesi Sosyal Bilimler Enstitüsü Iktisat Doktora programında, Prof. Dr. Halil TUNALI danışmanlığında "Finansal Krizler için Erken Uyarı Sistemi Modellemesi: Dinamik Probit Model Yaklaşımı" başlıklı tezden türetilmiştir.

\section{'Dr., İstanbul Üniversitesi, Sosyal Bilimler Enstitüsü, İktisat Anabilimdalı, İstanbul, Türkiye}

ORCID: G.P. 0000-0002-8324-6270

\section{Sorumlu yazar/Corresponding author:} Gülden POYRAZ,

İstanbul Üniversitesi, Sosyal Bilimler Enstitüsü, İktisat Anabilimdalı, İstanbul, Türkiye

E-posta/E-mail: poyrazgulden06@gmail.com

Başvuru/Submitted: 25.05 .2019

Revizyon Talebi/Revision Requested: 03.06.2019

Son Revizyon/Last Revision Received: 17.06.2019

Kabul/Accepted: 26.06 .2019

Atıf/Citation: Poyraz, G. (2019). Küresel finansal krizin öngörülebilirliği üzerine tartışmalar. İktisat Politikası Araştırmaları Dergisi - Journal of Economic Policy Researches, 6(2), 75-89. https://doi.org/10.26650/JEPR573664 


\section{EXTENDED ABSTRACT}

The crisis of 2007-2008 was the largest financial crisis since the 1930s and is characterised by being the deepest, most large scale and severe crisis of its predecessors. Davis and Karim (2008) suggested that the global financial crisis of 2007-2008 was revealed as a surprise for both most of the market participants and policymakers. In the early years of 2007, financial institutions such as the European Central Bank (ECB), BIS and the IMF couldn't anticipate the severity of the crisis or its scope of the international. The recent financial crisis has triggered significant debates concerning economic theory and policy. The most important discussions focused on the question 'why was the crisis not foreseen?'. In this context, the question that why the global financial crisis in 2007-2008 is not foreseen is considered in three different perspectives. The first view is that the crisis could not be predicted by economists in general and that the recent financial crisis emerged as a surprise for most of the academicians and policy makers. In this respect, the most important criticism towards the question "Why wasn't the crisis predicted" is directed to the Dynamic Stochastic General Equilibrium models. These models include real sector variables except for money supply and interest rates. Dynamic Stochastic General Equilibrium models provide detailed predictions about the real economy. Moreover, the equations that composed in these models do not include finance and banking sectors despite the fact that their failures may turn the general economy upside-down. Therefore, It is indicated that by their nature of these models don't have the appropriate tools in order to struggle with the financial crisis and a suitable structure that cover the dynamics of the crisis. Considering that the long-term stagnations were due to the balance sheet problems partly in the financial sector as a result of the collapse of asset prices since the late 1980s (Bezemer, 2009: 19), necessitate the inclusion of financial markets to these models. Existing deficiencies in Dynamic Stochastic General Equilibrium models emerged along with the global crisis. Thus, since 2016, The Reserve Bank of Australia (RBA) began to use a new macroeconomic model called MARTIN (Macroeconomic Relationships for Targeting INflation) in its policy analysis and forecasts. In this respect, the study provides a discussion of the methods used by economists in analysing the economy and formulating their proposals. Within this scope, two explanations can be given to the question of why the 2008 global financial crisis could not be predicted. The first was that the failure of economists to expand these models in a way to cover the risk of crisis or consciously prefer to do not so (Davies and McGoey, 2012). The second explanation is the fact that the Dynamic Stochastic General Equilibrium models that widely used today keep the especially financial markets out of the model, underestimated the new financial system created by financial institutions and weaknesses in risk assessment techniques. Considering all these factors, it may help explain the question of why the 2007-2008 global crisis couldn't be predicted. The second view is that the crisis was predicted by some of the economists, but 
these predictions were not considered and ignored. As mentioned above, the idea that "no one could foresee the crisis" is a widespread opinion among the public, policymakers, and economists in general. Contrary to this view, although the economist/finance managers who are predicting the crisis warned that predominantly financial globalization, the real estate market of the U.S. and derivative products have significant risks, the question of ignoring why these warnings can be answered with a tendency towards "strategic ignorance". The last opinion is the approach that economics/economists do not need to predict the crisis. This approach explains in the framework of the efficient market hypothesis and rational expectations that economics or economist does not need to predict the crisis. 


\section{Giriş}

Krizler, insanların gelecek hakkında mükemmel bilgiye sahip olma konusundaki yetersizliğin ifadeleridir. 2007-2008 krizi, 1930'lu yıllardan bu yana görülen en büyük finansal kriz olup, bu kriz kendinden önceki krizlerin en derini, en geniş çaplısı ve en şiddetlisi olma niteliğine sahiptir. Davis ve Karim (2008), 2007-2008 küresel finansal krizinin hem piyasa katılımcıların hem de politika yapıcıların çoğu için sürpriz olarak ortaya çıktığını ileri sürmüşlerdir. 2007 yılı başlarında Avrupa Merkez Bankası (ECB), BIS ve IMF gibi finansal kurumlar, krizin şiddetini ya da uluslararası kapsamını öngörememişlerdir.

Ana-akım iktisatçılar tarafından öngörülemeyen bu kriz, ana-akım iktisatçıların ve teorilerinin öngörme kapasitesini tartışmaya açmış ve ana-akım iktisadın bugünkü hakim konumunu yakın gelecekte koruyup koruyamayacağı sorusu, giderek daha fazla iktisatçı tarafından sorgulanır hale gelmiştir. Küresel finansal krizin yaşanacağına ilişkin ana-akım dışı (heterodoks) iktisatçılar tarafından yapılan uyarılara ve geçmişte benzer örnekleri de bulunmasına rağmen ana-akım iktisat bu krizi neden öngörememiştir? Bu sorunun cevabıyla ilgili üç farklı görüş söz konusudur: (Uygur, 2012: 2).

- Bu görüşlerden ilki, krizin genel olarak iktisatçılar tarafından öngörülemediği şeklindedir.

- Diğer bir görüş ise, krizin bazı iktisatçılar tarafından öngörüldüğü, fakat bu öngörülerin dikkate alınmadığı, göz ardı edildiği şeklindedir. Dolayısıyla, iktisatçıların krizi neden öngöremedikleri sorusuna, var olan kriz uyarılarını neden dikkate almadıkları sorusu da eklenmektedir.

- Son olarak ve tümüyle farklı bir görüş ise iktisadın/iktisatçıların kriz öngörüsünde bulunmaması gerektiğini ifade eden yaklaşımdır.

Kriz sonrasında ise, birçok ana-akım iktisatçı bu krizi açıklayabilmek için Nassim Nicolas Taleb'in (2015) “siyah kuğu” olgusuna başvurmuş ve krizi siyah kuğu gibi sıra dişı şekilde nadir görülen, öngörülmesi imkânsız, oyunun kuralını değiştirecek boyutta olan ve olay gerçekleştikten sonra açıklanabilir ve öngörülebilir hale getirecek birtakım açıklama getirme çabası olarak sunmuşladır. Taleb'e göre 'siyah kuğu körü olmak' çok tehlikeli sonuçları olsa bile, bazı önemli gelişmelerin gerçekleşme olasılığını görmezden gelme eğilimi yaratmaktadır. Geleceğe aşırı güveniyorsanız ve siyah kuğu körü iseniz - ki hepimiz ortalamalara odaklanıp sapmalara dikkat etmeme eğilimliyiz' - öngörüde bulunmak 'tehlikeli' sonuçlara yol açabilir.

\footnotetext{
1 Mohamed El-Erian (2009: 191) 'Piyasalar Çarpışınca' adlı kitabında sadece ortalamaya odaklanmayı şu cümlelerle eleştirmektedir: “...ppiyasalar dalgalanmaya başladığında yetkililer 'ortalamayı’ tutturmaya çalışırlar, ama eninde sonunda (normal) dağılımın uç noktalarına kurban giderler (...) diyelim ki insanların hayatını kurtarmak için bir nehrin derinliği 2 metreden 1,5 metreye indirilsin. Bu durumda yalnızca insanların ortalama boyunun 1,5 metreden fazla olduğunu bilmek yetmez; boyu 1,5 metreden kısa insanların sayısını da bilmek gerekir. Dağılım, ortalama kadar önemlidir."
} 
Howard Wainer (2007: 250) “En Tehlikeli Denklem” adlı çalışmasında, sapmaların görmezden gelinmesinin aşırı uzun bir süre devam ettiğini, dolayısıyla insanların kafasının karıştığını, birçok alanın kontrolden çıktığını, bu sapmaların dikkate alınmamasının çok ciddi sonuçlara neden olduğunu ve bu davranış yüzünden milyarlarca dolar zararla karşı karşıya kalındığını belirtmektedir. Bununla birlikte Roubini ve Mihn (2012) Kriz Ekonomisi adlı kitaplarında siyah kuğu olgusunu reddetmişler, bunun yerine krizi "beyaz kuğu" olgusu ile yani sistematik analize tabi olan, tümüyle olağan bir şekilde ortaya çıkan, aynı senaryoyu tekrarlayan ve öngörülebilen bir sürecin ürünü olarak nitelendirmişlerdir. Roubini’ye göre krizler istisna değil standarttır. Bu tüm krizlerin aynı olduğunu söylemek anlamına gelmemektedir. Krizlerin özellikleri birbirinden farklılık gösterebilir, fakat pek çok açıdan tanıdık bir senaryoya bağlı kalmaktadırlar. Krizler, yarattıkları tüm kaosa rağmen belli alışkanlıkları olan olgulardır (Roubini ve Mihn, 2012: 23-25).

Yüzyıllar boyunca ortaya çıkan finansal krizleri verilere dayalı bir yaklaşım çerçevesinde açıklama yolundaki en önemli girişim Reinhart ve Rogoff'un (2010) 'Bu Sefer Farklı: Finansal Çılgınlığın 800 Yıllık Tarihi’ adlı çalışmasıdır. Reinhart ve Rogoff bu çalışmada 66 ülkenin sekiz yüz yıllık makroekonomik zaman serilerini incelemiş ve krizlerin ortak temasının, aşırı borç birikiminin sistematik risklere yol açtığını vurgulamışlardır. Yazarlar ayrıca, geçmiş kriz deneyimleri ile günümüzdeki krizlerin benzer yönlerini ortaya koymuş ve son krize ilişkin 'biz bunu daha önce de yaşadık' tezini işlemişlerdir.

\section{2. İktisatçılar Krizi Neden Öngöremedi?}

“Kriz neden öngörülemedi?”, “Krizi öngörmek için ana-akım iktisatın sahip olduğu teorik çerçeve ve kullandığı modeller mi yetersizdi?” gibi sorular bağlamında eleştiriler özellikle Dinamik Stokastik Genel Denge (DSGE) modelleriyle öne çıkan ana-akım makro iktisat teorisine yöneltilmektedir.

DSGE modelleri, Keynes ile başlayan makro iktisat teorisinin günümüzde geldiği son aşamadır. 1929 Büyük Buhran sonrası sanayileşmiş bir dünyada devamlı bir ekonomik büyüme gerçekleşmiş, durgunluklar giderek kısalırken toparlanmalar güçlü ve kalıcı olmuştur. 1960'lı yılların sonuna gelindiğinde ABD’de ekonomik genişleme dönemi uzun süreye yayılmış, iktisatçılar 'krizlerin modası geçti mi?' konulu konferanslar vermeye başlamışlardı. Krugman’a göre bu soru erken sorulmuştu: 1970’li yıllar da yüksek işsizlik ve enflasyonun bileşimi olan 'stagflasyon' ortaya çıkmış, stagflasyona karşı geliştirilen neoliberal politikaların başarılı olduğu ve ekonomik krizlerin gündemden çıktığ düşünülmüştü. 1990'lı yıllara gelindiğinde ise aynı soru tekrar sorulmaya başlanmıştır. Hem Robert Lucas (2003) hem de Ben Bernanke krizin patlak vermesinden birkaç yıl önce, ekonomide ara sıra gerilemeler yaşansa bile, krizlerin hatta şiddetli durgunlukların artık 
geride kaldığını ve makroekonominin en temel sorununun artık çözüldüğünü iddia etmişlerdir (Krugman, 2015: 6-7). Büyük ekonomik dalgalanmaların yaşanmayacağ inancının hakim olduğu ve "Great Moderation" olarak nitelendirilen bu dönemde makro iktisatçılar arasında bir uzlaşıya varılmış ve varılan uzlaşının ortaya koyduğu çerçeve Yeni Keynesyen paradigma ile Yeni Klasik İktisat / Reel Konjonktür teorisinin metodolojik ortaklığı üzerine inşa edilen Yeni Neo-Klasik Sentez modelleri olmuştur. Yeni Sentezin ampirik içeriği DSGE Modelleri ile güçlendirilerek, ana-akım iktisat teorisi alanındaki üstünlüğü pekiştirilmiştir.

Önde gelen merkez bankaları tarafından da kullanılan DSGE modelleri; rekabetçi piyasaları, esnek ücretleri ve rasyonel beklentilere sahip iktisadi ajanların zamanlar arası optimizasyon davranışı içinde bulundukları ve fiyatlar aracılığıla piyasaların temizlendiği varsayımları üzerine bina edilmektedir. Daha sonra bu modellere tekelci rekabet, katı ücret ve fiyatlar gibi bazı Keynesyen varsayımlar da dahil edilerek geliştirilmiştir (Semmler ve Gong, 2008: 29).

Etkin piyasa hipotezi ve rasyonel beklentiler çerçevesinde oluşturulan bu modeller, finansal piyasaların mükemmel bilgi akışına ve etkinliğe sahip olduğunu, piyasalarda oluşan fiyatların mevcut tüm bilgiyi yansıttığını ve rasyonel beklentiler varsayımı altında hareket eden iktisadi ajanların mevcut tüm bilgiyi kullanarak beklentileri şekillendirdiğini varsaymaktadır (Spaventa, 2009: 136). Ancak, temsili ajanların rasyonel davranışları varsayımına dayanan etkin piyasa hipotezi, krizlerle karşılaştığında tıkanmaktadır. Çünkü rasyonel iktisadi ajanların kararları sonucunda kriz değil, refah artışının ortaya çıkması beklenmektedir. Oysaki iktisadi ajanların, finansal piyasalarda duygusal ve hormonal reaksiyonlardan önemli ölçüde etkilendikleri bilinmekte dolayısıyla bu ajanlar rasyonel beklentiler hipotezine göre hareket etmemekte; aksine heuristic (sezgisel) karar alma süreci kullanarak ve yeni bilgilere karşı hareketsiz kalarak, davranışlarını 'sınırlı rasyonellik' kavramı çerçevesinde oluşturmaktadırlar (Colander v.d., 2009: 7-8).

DSGE modelleri, mal ve emek piyasalarının işleyişinde mikroekonomik temellere dayanmalarına rağmen oluşturdukları denklemlerde, başarısızlıkları genel ekonomiyi altüst edebileceği gerçeğine rağmen, finans ve bankacılık kesimine hiç yer vermemektedir. ${ }^{2}$ Uluslararası Ödemeler Bankası (BIS) da bu modellerin en önemli zaaflarından birinin finansal piyasaları modellemedeki eksikliği olduğunu belirtmiştir. Finansal piyasalara yer vermeyen bu modeller, finansal piyasaların neden olduğu konjonktör dalgalarının makroekonomik etkilerini değerlendirme imkanını ortadan kaldırmakta, finansal kırılganlık,

\footnotetext{
2 Joseph E. Stiglitz (2011: 594) “Rethink Macroeconomics: What Failed, and How to Repair It” başlıklı çalışmasında DSGE modellerine dahil edilmeyen kritik alanları şu şekilde sıralamaktadır. Bu modellerde; Bilgi asimetrisi, finansal piyasalar, aşırı borçlanma, temerrüt, aktörlük sorunu ve son olarak dışsallıklar yer almamaktadır.
} 
likidite sıkışıklığı veya finansal sistemlerin döngüselliği gibi sorunların analizini de yapamamaktadır (Tovar, 2008: 4). Ayrıca bu modellerde deregülasyonlar ve yeni yapılandırılmış türev ürünlerin makroekonomik sistem üzerindeki etkileri de ihmal edilmiştir. Yeni yapılandırılmış finansal türev ürünler lehine geliştirilen bu modeller, mevcut durumu sunmaktan ziyade ikna etmeye dayalı olması, daha fazla finansal türev ürününün geliştirilmesinin sistemi daha az riskli hale getirdiği ve bireyin refahını artırdığı algılamasını doğurmuştur. Bu algı, küresel finans krizi öncesinde yatırımcıların aşırı kaldıraçla pozisyon almalarına neden olmuş ve bu durumun yarattığı tehlike de yeterince dikkate alınmamıştır. Willem Buiter (2009) DSGE modellerinin, ilgilendiği tüm değişkenleri dışladığını belirterek bu modelleri "pahalı bir vakit kaybı" olarak nitelendirmektedir (Spaventa, 2009: 136).

2007 küresel finans krizi sonrasında Almanya’da toplanan Dahlem Çalıştay’nın sonuç metninde, yaşanan büyük ekonomik çöküşün akademik iktisadın entelektüel krizi olduğu ileri sürülmüştür (Akçay, 2014: 50). Çalıştay’a katılan iktisatçılara göre, yaşanan finansal krizin nedeni finansal piyasaların karmaşıklığı veya iktisatçıların yaşanan gelişmeleri anlayamaması değildir. Sorunun temelinde, iktisatçıların kullandıkları modellerin gerçekçi varsayımlara dayanmaması (Colander v.d., 2009: 3-4) ve varsayımların potansiyel zaaflarını bilmeyen ajanların modellerin eksikliklerini ihmal etmelerinden kaynaklanmaktadır (Colander v.d., 2009: 6). Özellikle finans alanında kullanılan risk değerleme modellerinin benimsedikleri varsayımlarının gerçekçi olmaması ve bu modellerin kırılgan yapıda olması piyasa oyuncularını, ekonomik sistemin işleyişini bu kırılgan modeller vasıtasıyla anlamaya çalışmışlardır (Colander v.d., 2009: 3-4).

Kriz öncesinde kullanılan bu modeller, birçok sanayileşmiş ülkede 1980'lerin ortalarından itibaren görülen düşük enflasyon ve makroekonomik istikrar ortamında tasarlandı̆̆ 1 için iktisadi faaliyetlerin sürekli tekrarlanan genişleme - daralma dinamiklerini kapsamamaktadır (Bernanke, 2010: 17). Dolayısıyla kurguları gereği bu modellerin finansal krizle mücadele için uygun araçlara ve krizin dinamiklerini kapsayacak uygun bir yapıya sahip olmadığı da belirtilmelidir.

$\mathrm{Bu}$ eleştiriler çerçevesinde ana-akım iktisat teorilerinin temel sorunu, gerçek dünyanın tarihsel-kurumsal olgularına yer vermeyen matematiksel yöntemlerin, sosyal olguların analizinde yararlı ve uygun 'tek' yol olduğunu yönündeki ısrarlarıdır denebilir (Lawson, 2009: 776). Örneğin, iktisat tarihçisi Donald McCloskey, yaklaşık kırk yıl önce şu tespitte bulunmuştur: "Kırk yıl boyunca iktisadı matematikleştirme çabalarına yapılan yatırım, iktisatçıları, tarih cahili olmaktan ziyade matematik cahili olduklarını kabul etmekten uzaklaştırd1.” (aktaran Gorton, 2018: 112). Aynı doğrultuda Nassim Nicholas Taleb de siyah kuğu adlı kitabında, 
"Matematik yüzde yüz doğrudur, yüzde doksan dokuz falan değil. Matematiğin bu özelliği belirsizliklerle uğraşmak istemeyen mekanik zihinleri kendine çeker. Ne yazık ki dünyayı mükemmel matematiğe uydurabilmek için bir yerlerde hile yapmanı, varsayımlarla oynamalar yapmanız gerekir (Taleb, 2015: 344) (...) Pek çok durumda bizdeki matematik akrobatlığına sahip olmaktansa hiçbir modele sahip olmamanın daha iyi ve daha akıllıca olacă̆ını", belirtmiştir (Taleb, 2015: 437).

Taleb'in iktisatta yoğun matematik kullanımı ile ilgili eleştirisine tepki Nobel ödüllü iktisatçı R. Shiller (2013)'den gelmiştir. Shiller'e göre,

“iktisatta kullanılan tüm matematik şarlatanlık değildir. İktisadın kaçınılamayacak kadar önemli kantitatif bir yanı bulunmaktadır. Buradaki zorluk, iktisadi modelleri, iktisadın indirgenemez insan unsuruna uygun hale getirmek için gereken ayarlamaları matematiksel kavrayışı ile birleştirmektir. İktisat geliştikçe, yöntem ve kaynaklar da gelişecek, böylece iktisat bilimi daha da güçlenecek ve şarlatanlar açı̆̆a çıkacaktır."

Chicago Ünivesitesi finans profersörü Raghuram Rajan, "İktisatçılar Krizi Neden Öngöremedi?” başlıklı makalesinde iktisatçıları farklı bir yönden eleştirmektedir. Rajan iktisatçıların krizi öngörme konusundaki genel başarısızlığını üç nedene bağlamaktadır. Bu nedenlerden birincisi, iktisatçıların birbirinden ayrışmış dar kapsamlı konularda çalışmaları ve diğer alanlara ilgi göstermemeleridir. Oysaki öngörü yapabilmek için ekonominin, finansın hatta diğer bilim dallarının farklı konularını takip etmek gerekmektedir. İkinci neden, öngörü yapmanın zorluğu ve iktisatçıların bu konuda çekingen davranmalarıdır. İktisatçılar, öngörüde bulunmanın önemli ölçüde itibar riski taşıdığını düşünmektedirler. İktisatçıların krizi öngörme konusundaki başarısızlığının üçüncü nedeni ise, kendilerini gerçek dünyadan soyutlamalarıdır. Gerçek dünyanın karmaşıklığı ve kısa dönem konjonktür dalgalarını açıklamanın zorluğu, öngörüde bulunmanın zorluğu ile birleşince iktisatçılar ekonomideki gelişmelere uzak durmaktadırlar (Rajan, 2011: 2).

Yukarıda belirtilen tüm bu argümanlara rağmen bu konuda pek çok çalışması olan David Colander, iktisatçıların krizleri öngöremediği için suçlanmaması gerektiğini; zira makroekonomin, sürekli değişen karmaşık bir sistem olduğunu ve dolayısıyla birçok yönünün tahmin edilmesinin mümkün olmadığını belirtmektedir (Colander, 2010: 1).

\section{Krizi Öngören İktisatçılar}

Ocak 2009'da, ABD Başkan yardımcısı Dick Cheney’e Associated Press'e verdiği bir röportajda 1929 Büyük Buhranından bu yana görülen en büyük finansal krizi, yönetimin nasıl olup da öngöremediği sorulduğunda Cheney'in yanıtı netti. Cheney, "Hiçbir yerde, hiç kimse ne olduğunu anlayacak kadar akıllı değildi”" dedi ve ekledi: "Hiç kimsenin gelen krizi görebildiğini sanmiyorum.” (Terkel, 2009). 
“Krizi kimse öngöremedi” düşüncesi genel olarak kamuoyunda, politika yapıcılar da ve iktisatçılar arasında yaygın bir kanıdır. 2007 - 2008 finans krizi esnasında FED başkanlığını yapan Ben Bernanke "Karar Alma Cesareti" (2016: 106-109) adlı kitabında, finansal krizi öngöremediklerini ve finansal krizi öngörmedeki zorlukları şu şekilde ifade etmektedir:

“...çoğu kez mükemmel olmasa da yapbozun birçok parçasını görüyorduk. Fakat bu parçaların bir araya gelerek büyük bunalım ile klyaslanabilecek, hatta onu aştığı tartışılır bir finansal krizi üretmekte olduğunu anlayamadık, belki de "tahayyül edemedik" demek daha doğru. (...) finansal sistemin kendisinde yapısal zayıflıklar olmasaydı, kasırga tüm ekonomimizi yıkımın eşiğine getirecek boyutta hasar yaratmazdl. Amerikan finans sistemi giderek karmaşık ve opak bir yap haline gelmişti, finansal düzenleme sistemi köhneleşmiş ve tehlikeli bir biçimde parçalara ayrılmışt. Ayrıca borca, özellikle de kısa vadeli borca aşırı bel bağlanması sistemi istikrarsız kılmıştı. Bu tetikleyiciler ve yapısal zayıflıklar arasındaki etkileşimin olağanüstü karmaşıklı̆̆ı, krizin tüm doğasını ve boyutunu neden çok az kişinin öngörebildiğini açıklıyor."

Bütün resim tam anlamıyla belirginlik kazanmamış olsa da, birkaç iktisatçı, politika yapıcı veya finans yöneticisi krizin yaklaşmakta olduğu konusunda uyarılarda bulunmuştu. Örneğin 2003 'te Kansas City Fed'in Jackson Hole Wyoming'de düzenlediği konferansta Uluslararası Ödemeler Bankasından (BIS) Claudio Borio ve William White hazırladıkları raporda, uzun finansal sakinlik dönemlerinin yatırımcıları ve finansal kurumları sorumsuz davranmaya ve aşırı riskler almaya ittiğine dikkat çekmişlerdi. Dot.com teknoloji balonunu doğru bir şekilde öngören Robert Shiller de konut piyasası ile ilgili yaptığı araştırmalarında, geçtiğimiz yüz yıl boyunca konut değerlerinin enflasyona paralel bir artış gösterdiği sonucuna ulaşmış ve 2000 yılının başlarındaki iki haneli değer artışının mantığa aykırı bir durum oluşturduğunu, 2005 yılında konut fiyatlarındaki artış düzeyinin kalıcı olmayacağı konusunda uyarılarda bulunmuştu (Kansas, 2009: 41). Chicago Üniversitesi'nde Finans Profesörü olan Raghuram Rajan (2005: 2) bankacıların ve borsa simsarlarının ücretlendirme şeklinin onları çok fazla risk alma konusunda cesaretlendirdiğini ve küresel finans sistemini krize karşı savunmasız bıraktığını belirtmiştir. Ulusal Ekonomik Araştırma Bürosu³ Başkanı Martin Feldstein (2007: 1) konut fiyatlarının düşmesi ve evlerinin değerleri üzerinden borçlanan ev sahiplerinin sayısındaki azalmaya dikkat çekmiş, "konut fiyatlarındaki ve tüketim harcamalarındaki düşüşlerin” ekonomiyi durgunluğa sürükleyebileceğini uyarısında bulunmuştur.

New York Üniversitesi’nde iktisat profesörü olan Nouriel Roubini ise, 2006 y1lı Eylül ayında Uluslararası Para Fonu (IMF) toplantısında yaptığı konuşmasında, "Kriz gelmek üzere. Amerika, muhtemelen hayatında ilk kez karşılaşacak: konut balonunun sönmesi, petrol şoku, hızla düşen tüketici güveni ve kaçınılmaz derin bir ekonomik durgunluk...” dedikten

\footnotetext{
3 National Bureau of Economic Research (NBER)
} 
sonra konuşmasına şu şekilde devam etmiştir: Ev sahipleri mortgage kredilerini ödeyemedikçe, trilyon dolar değerindeki mortgage destekli teminatların çözülmeye başlayacağını, tüm küresel finans sisteminin sarsılarak durma noktasına geleceğini; henüz gerçekleşmemiş olan bu konut fiyaskosunun finansal sistemde sistematik bir probleme neden olabileceğini, hedge fonlar ve yatırım bankalarıyla birlikte Freddie Mac ve Fannie Mae gibi devlet destekli finansal devleri iflasa sürükleyebileceğini, iki büyük yatırım bankasının batacağını ve diğer büyük finansal kurumların da bağımsız kuruluşlar olarak ayakta kalamayacağı uyarısında bulunarak konuşmasını bitirmiştir (Roubini ve Mihm, 2012: 10).

Ayrıca, bazı ekonomistler uzun bir süredir ABD'nin kendi ekonomisini ve parasını çökertecek şeklide borçlandığını ve dış borcunun hızla baş edilemez noktaya doğru ilerlediğini belirtmekteydiler. Özellikle, Maurice Obstfeld ve Kenneth Rogoff (2009) ABD’nin cari açığının sürdürülemez boyutta olduğu uyarısında bulunmuş ve Financial Times'ın ekonomi editörü Martin Wolf da 18 Ağustos 2004 tarihli köşe yazısında “ $A B D$ şuanda konforlu bir şekilde yıkıma doğru yol almaktadır.” şeklinde yazmıştır.

$\mathrm{Bu}$ iktisatçılar ve yorumcular krizin yaklaşmakta olduğu konusunda uyarılarda bulunmalarına rağmen, uyarıları neden dikkate alınmadı? veya görmezden gelindi? Öncelikle, standart modellerin yapısını incelediğimizde, bu modellerin temelini oluşturan görüş, piyasaların ve ekonomilerin doğaları gereği istikrarlı olduğu ancak geçici olarak dengeden saptıkları şeklindedir. Bu zımni görüş nedeniyle iktisatçıların çoğu, sistematik kriz ile ilgili uyarı yapma gereği duymamış, sistematik krizler konusunda uyarı yapanların çalışmalarını da görmezden gelmiştir (Colander v.d., 2009: 2). Bu durum, piyasa mekanizmasının kendi yanlışlarını ve aşırılıklarını düzelteceği ile ilgili bir kanı olmanın ötesinde, söz konusu uyarıları "görmezden gelme"”nin kullanışlılığı ile de ilgilidir. L. McGoey (2012), "görmezden gelme” kavramını rahatsız edici bilgiyi saklama ve kasten onu izole etme eylemi olarak tanımlamış ve "görmezden gelme" eyleminin iki temel işlevine dikkat çekmiştir. Bu eylemin ilk işlevi, sonunda yıkıcı etkiler ile sonuçlanacağının bilinmesine rağmen sosyal suskunluğun, menkul kıymetleştirme yoluyla yaratılan türev ürünler üzerinden önemli miktarlarda komisyon geliri elde eden bankacılara, derecelendirme kuruluşlarına ve aracılara yüksek karlı faaliyetlerini sürdürme imkanı sağlamasıdır. İkinci işlevi ise, riskin tespit edilmesinin imkansız olduğunu ileri sürenlerin, faaliyetlerini temize çıkarmak için önceki suskunluğu kullanmasıdır. Finansal Kriz Araştırma Komisyonu Başkanı Phil Angelides'ın sözleri "görmezden gelme" eylemini destekler niteliktedir: "Bazılarına göre krizin öngörülmesi mümkün değildi. Aslına bakılırsa, birçok uyarı sinyali görmezden gelindi ya da örtbas edildi.” (Sina, 2011).

Bu uyarıları görmezden gelme eğilimi söz konusu uyarıların ana-akım iktisada uygun bir dille ortaya konulmaması ile de ilgilidir. Örneğin 2006 yılında N. Roubini’nin IMF 
toplantısında kriz ile ilgili yaptığı uyarılar, Roubini’nin öngörülerinin matematiksel bir modele dayanmadığı; tüketici güven endeksi, tahakkuk ve mortgage faiz oranlarını kullanarak yaptığı tespitlerin yeterli olmayacağı gerekçesiyle iktisat teorilerine son derece bağlı ekonomistler tarafından eleştirilmiştir (Osmanoğlu, 2012: 19).

\section{4. İktisadın / İktisatçının Kriz Öngörüsü Yapmasına Gerek Yoktur}

Krugman, ana-akım iktisatçıların da ifade ettiği "krizi kimse öngöremedi” savını şu cümlelerle eleştirmektedir: Mevcut krizi çok az sayıda iktisatçı öngördü, fakat öngörüdeki bu başarısızlık iktisadın en önemli sorunu değildir. Daha da önemli sorun, piyasa ekonomisini felakete sürükleyebilecek piyasa başarısızlıklarının oluşabilme ihtimali karşısında iktisat mesleğinin kör olmasıdır. Krugman, öngörüdeki bu başarısızlığın ana-akım iktisadın "etkin piyasalar hipotezi" ve bu hipotezin bir gereği olan "ekonomide balon (bubble) olmaz" kavramına olan inançtan kaynaklandığını belirtmektedir. Krugman’a (2009) göre etkin piyasalar hipotezi balonun şişirilmesinde önemli bir rol oynamıştır.

Krugman'ın “etkin piyasalar hipotezine” yönelttiği bu eleştirisine John Cochrane (2009) şu ifadelerle karşılık vermektedir: "krizi öngöremediğimizi söylemek eğlenceli, fakat etkin piyasalar hipotezi, piyasaların nasıl hareket edeceğini kimsenin öngöremeyeceğini ifade eder. Dolayısıyla krizi öngöremediler diye etkin piyasalar hipotezini itibarsızlaştırmaya çalışmanın yararı yoktur.”

Yeni klasik makro teorinin kurucusu ve Nobel ödüllü iktisatçı R. Lucas (2009) The Economist dergisinde yayınlanan bir mülakatında finansal krizin, iktisat biliminin krizi olduğu yönündeki eleştirileri şu ifadelerle reddetmektedir:

"2008 finansal krizi öngöremediğimiz veya önleyemediğimiz için iktisatçllarla ilgili büyük bir hayal kırıklı̆̆ var. Makro iktisatçılar, değersiz hatta zararlı matematiksel modeller üzerine eğitilen ve bu nedenle anlamlı iktisat politikalarl yürütmekten aciz kayıp bir nesil olarak karikatürize edilmektedir. Bu değerlendirme doğru değildir. Finansal varlık fiyatlarında ani düşüsleri öngören modellere şu anda ya da daha sonra sahip olamayacă̆ız. Bu yeni bir şey değil. Bu 40 yılı aşkın bir süredir Eugene Fama tarafindan geliştirilen etkin piyasalar hipotezi olarak biliniyor. Ĕger bir iktisatçı finansal krizi bir hafta önceden öngörebilen bir formüle sahip ise bu formül mevcut bilginin bir parçası haline gelecek ve fiyatlar bir hafta önceden düşecektir. Etkin piyasalar hipotezinden politika yapımı amacıyla çıkaracağımız en önemli ders şudur; kriz ve durgunlukların üstesinden gelmek için balonları tanıyıp patlatacak merkez bankacılar ve düzenleyiciler bulmaya çalışmanın bir yararı yoktur."

Saint Paul da (2009) iktisadın ve iktisatçıların krizi öngörememesi ile ilgili eleştirilere Lucas ile benzer ifadelerle cevap vermektedir: 
“...i) Krizleri öngörmek iktisatçıların görevi değildir. Çünkü iktisatçılar nadir görülen sistematik olayların modellemesiyle uğraşmaz. Birileri iktisatçıları krizi öngöremedikleri için faydasız ve işe yaramaz olarak düşünebilirler. Ancak bu, AIDS veya deli dana gibi rahatsızlıkları öngöremedikleri için doktorların yetersiz ve işe yaramaz olduklarını söylemek kadar saçmadir.

ii) Kriz doğası gereği öngörülemez. Örneğin herhangi bir makroekonomik teori, konut balonunun ortasında, iki yıl sonrası için finansal bir kriz öngörürse bunu dikkate alanlar krizin hemen çıkmasına neden olur ve bu da teoriyi geçersiz kılar. İktisat, dŏga bilimlerinden farklıdır, yani bir fiziki olayı öngörmekle sosyal bir olguyu öngörmek arasında fark vardır. Çünkü piyasa katılımcıların piyasanın geleceğine yönelik inançları ve beklentileri geleceği etkilemektedir.

iii) Öngörü becerisini matematiksel teknikler ve modeller dışındaki araçlarla nasıl geliştirileceğini bilmek zordur. "Genel bir bakış açısı" bize, kurumsal çevre veya insan doğasının rolü hakkında bir fikir sunarken; “öngörü”, matematiksel olarak formüle edilen ve matematiksel teknikleri kullanan nicel bir uygulamadır. Dolayısıla hem öngörünün yetersiz olduğunu hem de çok fazla matematiksel model kullanıldı̆̆ını söylemek çelişkilidir.

iv) Ekonomi son derece karmaşık bir sistem olduğu için ekonominin bir bütün olarak işleyişini anlamak son derece zordur. Inançların, kurumların ve beklentilerin rolü göz önüne alındı̆̆ında sistem daha da karmaşık hale gelir. Ekonomiyi yönlendiren güçlerin etkileşimini anlamaya çalışırken doğa bilimcilerinden (fizikçilerden) çok daha zorlandığımıza hiç şüphe yoktur. Sonuç olarak iktisat gerçek dünyanın nasıl çalıştı̆̆ını anlamada yardımcı olmasını umduğumuz mütevazı bir bilim dalıdır."

\section{Tartışma ve Sonuç}

Bu çalışmada 'Kriz neden öngörülemedi?' sorusuna üç farklı görüş ile cevap verilmeye çalışılmıştır. Bu görüşlerden ilki, krizin genel olarak iktisatçılar tarafından öngörülemediği şeklindedir. 2007-2008 finansal krizin akademisyenler ve politika yapıcıların çoğu için sürpriz olarak ortaya çıktığı ve "hiç kimse krizi öngöremedi” görüşü yaygın olarak kabul edilmektedir. Bu doğrultuda, "Kriz neden öngörülemedi?”, sorusuna en önemli eleştiri DSGE modellerine yöneltilmektedir. Bu modeller, para arzı ve faiz oranları hariç, reel sektör değişkenlerini içermektir. DSGE modelleri reel ekonomi hakkında ayrıntılı tahminler sunmakla birlikte, finansal sektör ve bu sektörün ürettiği fon akışı bu modellerde yer almamaktadır. Uzun süreli durgunlukların 1980'lerin sonlarından bu yana varlık fiyatlarındaki çöküşün bir sonucu olarak kısmen de olsa finansal sektördeki bilanço sorunlarından kaynaklandığı düşünüldüğ̈̈nde (Bezemer, 2009: 19), bu modellere finansal piyasaların dahil edilmesini gerekli kılmaktadır. Küresel krizle birlikte DSGE modellerinde 
var olan eksikliklerin ortaya çıkmasıyla Avustralya Merkez Bankası (RBA) politika analizi ve tahminlerinde 2016 yilından itibaren MARTIN (MAcroeconomic Relationships for Targeting INflation) adlı yeni bir makro ekonomik model kullanmaya başlamıştır.

Bu çerçevede, 2008 küresel finans krizinin neden öngörülemediği sorusuna iki açıklama getirilebilir: bunlardan ilki iktisatçıların, kriz riskini de kapsayacak şekilde bu modelleri genişletmedeki başarısızlıkları ya da bilinçli olarak bunu tercih etmemeleridir (Davies ve McGoey, 2012: 69). Diğeri ise günümüzde de geniş bir şekilde kullanılan DSGE modellerinin özellikle finansal piyasaları modelin dışında tutması, finansal kurumlar tarafından oluşturulan yeni finansal sistemin hafife alınması (Osmanoğlu, 2012: 21) ve risk değerleme tekniklerindeki zaaflarıdır. Bütün bu faktörler dikkate alındığında, 2007-2008 küresel finans krizinin neden öngörülemediği sorusunu açıklamaya yardımcı olabilir.

İkinci görüş ise, krizin bazı iktisatçılar tarafından öngörüldüğü, fakat bu öngörülerin dikkate alınmadığı, göz ardı edildiği şeklindedir. Yukarıda da ifade edildiği gibi "Krizi kimse öngöremedi” düşüncesi genel olarak kamuoyunda, politika yapıcılar ve iktisatçılar arasında yaygın bir kanıdır. Bu görüşün aksine, "krizi öngören” iktisatçı/finans yöneticileri ağırlıkla finansal küreselleşmenin, ABD emlak piyasasının ve türev ürünlerinin önemli riskler taşıdığı hakkında uyarılarda bulunmalarına rağmen, bu uyarıların neden göz ardı edildiği sorusu 'görmezden gelme' eğilimiyle cevaplanabilmektedir.

Son görüş ise iktisadın/iktisatçıların kriz öngörüsünde bulunmasına gerek olmadığını ifade eden yaklaşımdır. Bu yaklaşım iktisadın ya da iktisatçının kriz öngörüsünde bulunmasına gerek olmadığı, etkin piyasa hipotezi ve rasyonel beklentiler çerçevesinde açıklamaktadır.

Finansal Destek: Yazar bu çalışma için finansal destek almamıştır.

\section{Kaynaklar}

Akçay, Ü. (2014). İktisadi kriz ve ana-akım iktisadın krizi. İktisat Dergisi, 527, 45-54.

Bernanke, B. (2010). On the implications of the financial crisis for economics. Board of Guvernors of the Federal Reserve System. Erişim adresi: http://www.federalreserve.gov/

Bernanke, B. (2016). Karar alma cesareti, yüzyılın en büyük finans krizi ve sonrası, (Çev. C. Feyyat, M. Demirsar). İstanbul: Scala Yayıncılik.

Bezemer, J. D. (2009). No one saw this coming. understanding financial crisis through accounting models. Erişim adresi: https://www.rug.nl/research/portal/files/2646456/09002_Bezemer.pdf

Cochrane, J. H. (2009). How did paul krugman get it so wrong? Erişim adresi: http://ricardo.ecn.wfu.edu/ cottrell/ ecn272/cochrane.pdf

Colander D., vd. (2009). The financial crisis and the systemic failure of academic economics. Kiel Institute for the World Economy, Working Paper, No.1489, 1-17.

Colander, D. (2010). The economics profession, the financial crisis, and method. Middlebury College Economics Discussion Paper, No. 10-38. 
Davies, W., McGoey, L. (2012). Rationalities of ignorance: on financial crisis and the ambivalence of neoliberal epistemology. Economy and Society, 41(1), 64-83.

Davis, E. P., Karim, D. (2008). Could early warning systems have helped to predict the sub-prime crisis? National Institute Economic Review, 206(1), 35-47.

El-Erian, M. (2009). Piyasalar çarpışınca: küresel ekonomik değişim çağı için yatırım stratejileri, (Çev. Ş. Tahir Gürçağlar). İstanbul: Scala Yayıncılık.

Feldstein, M. S. (2007). Houseing, credit markets and the business cycle. NBER Working Paper. Erişim adresi: https://www.nber.org/papers/w13471

Gorton, G. B. (2018). Finansal krizleri yanlış anlamak: krizlerin gelişini neden göremiyoruz? (Çev. M. Doğan). İstanbul: Boğaziçi Üniversitesi Yayınevi.

Kansas, D. (2009). Wall Street'in sonu. İstanbul: Türkiye İş Bankası Kültür Yayınları.

Krugman, P. (2009). How did economist get it so wrong?, The New York Times. Erişim adresi: http://www.nytimes. com/2009/09/06/magazine/06Economic-t.html

Krugman, P. (2015). Bunalım ekonomisinin geri dönüşü ve küresel kriz, (Çev. N. Domaniç). İstanbul: Literatür Yayınc1lik.

Lawson, T. (2009). The current economic crises: 1ts nature and the course of academic economics. Cambridge Journal of Economics, 33, 759-777.

Lucas, R. E. (2003). Macroeconomic priorities. The American Review, 93(1), 1-14. http://www.princeton. edu/ markus/misc/Lucas2003.pdf

Lucas R. E. (2009). In defence of the dismal science. The Economist. Erişim adresi: http://www.economist.com/ node/ 14165405

McGoey, L. (2012). The logic of strategic ignorance. The British Journal of Sociology, 63(3) 533-576. https://doi. org/10.1111/j.1468-4446.2012.01424.x

Obstfeld, M., Rogoff, K. (2009). Globol imbalances and the financial crisis: product of common causes, Federal Reserve Bank of San Francisco Asia Economic Policy Conference, Santa Barbara.

Osmanoğlu, H. (2012). Finansal krizin gizli doğası: Maça kızı efekti. İstanbul: Cinius Yayınları.

Rajan, R. G. (2005). Has financial development made the world riskier, NBER Working Paper, No.11728, 1-42.

Rajan, R. G. (2011). Why did economists not foresee the crisis? Project Syndicate, Erişim adresi: http://faculty. haas.berkeley.edu/mopp/Research/Rajan.pdf

Reinhart, C. M., Rogoff, K. S. (2010). Bu defa farklı: Finansal çılgınlı̆̆ın 800 yıllık tarihi, (Çev. L. Konyar). İstanbul: NTV Yayınları.

Roubini, N., Mihm, S. (2012). Kriz ekonomisi: Dünya ekonomisinin çöküşü ve geleceği, (Çev. I. Tezcan). İstanbul: Pegasus Yayınları.

Saint - Paul, G. (2009). A 'modest' intellectual discipline. Vox CEPR Policy Portal. Erişim adresi:http://voxeu.org/ article/modest-intellectual-discipline-defence-contemporary-economics

Semmler, W., Gong, G. (2008). Keynes and modern macroeconomics, Middle East Technical University Studies in Development, 35(1), 29-60.

Shiller, R. J. (2013). Is economics a science? The Guardian. Erişil adresi: https://www.theguardian.com/business/ economics-blog/2013/nov/06/is-economics-a-science-robert-shiller

Sina, R. (2011). Göz göre göre kriz. Deutsche Welle (DW). Erişim adresi: https://www.dw.com/tr/göz-göre-görekriz/a-14802306

Spaventa, L. (2009). Economists and economics: What does the crisis tell us? Center for Policy Research Policy Insight, No: 38: 132-142. 
Stiglitz, J. E. (2011). Rethink macroeconomics: what failed, and how to repair it. Journal of The European Economic Association, 9(4), 591-645.

Taleb, N. N. (2015). Siyah kuğu: Olanaksız görünenin etkisi (Çev. N. Arıbaş). İstanbul: Varlık Yayınları.

Terkel, A. (2009), Cheney: no one could have predicted the financial crises, just as no one foresaw. Think Progress. Erişim adresi: https://thinkprogress.org/cheney-no-one-could-have-predicted-the-financial-crisis-just-as-noone-foresaw-9-11-664c49473480\#.d9fp67fzc

Tovar, C. E. (2008). DSGE models for policy analysis at central banks: an overview of issues and challenges. Bank for International Settlements (BIS). Erişim adresi: http://www.hkimr.org/uploads/seminars/163/sem _ paper_0_288_tovar-dsge-models-for-policy-analysis-at-central-banks.pdf

Uygur, E. (2012). Küresel bunalım, iktisat politikaları, yöntemleri ve eğitimi. Türkiye Ekonomi Kurumu Tartışma Metni.

Wainer, H. (2007). The most dangerous equation, American Scientist, 95(3), 249-256.

Wolf, M. (2004), America is now on the comfortable path to ruin. Financial Times. Erişim adresi: https://www. ft.com/content/488f2e14-f07a-11d8-a553-00000e2511c8 
